
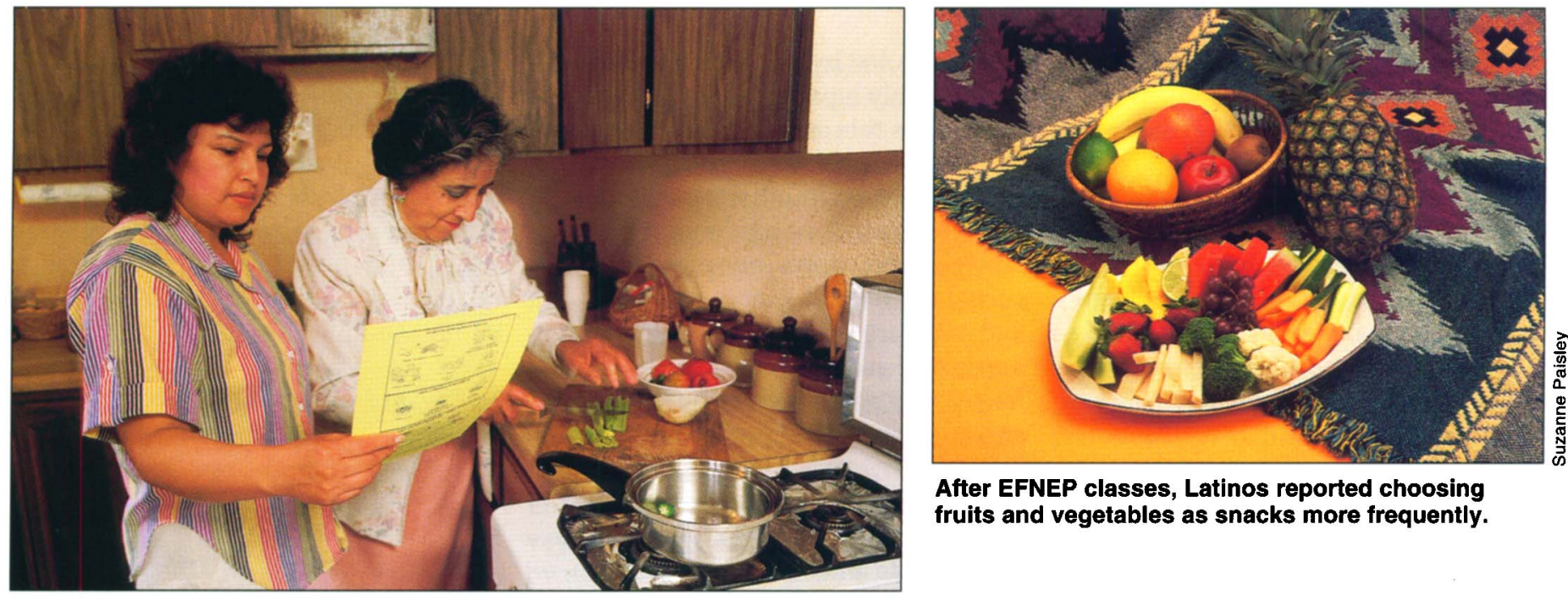

After EFNEP classes, Latinos reported choosing fruits and vegetables as snacks more frequently.

\title{
Latinos improve food habits through nutrition education
}

\author{
Lucia L. Kaiser $\sqcup$ Jeanette M. Sutherlin $\square$ Sallie C. Yoshida \\ Suzanne P. Murphy $\square$ Stuart D. Bresnick
}

\begin{abstract}
Identifying the health concerns and barriers to change of diverse audiences is essential to successful nutrition interventions that reduce the risk of chronic disease. This article reports some of the current activities that the Expanded Food and Nutrition Education Program (EFNEP) is undertaking in California to assess the needs of Latino clients and to develop culturally appropriate tools to evaluate changes in food-related behaviors. Latinos in Fresno County reported a number of improvements in food-related behaviors after attending EFNEP nutrition classes, particularly in the areas of reducing fat intake, using a wider variety of fruits and vegetables, shopping wisely and thawing meat safely. Nutrition educators working with Latinos need to find new ways to reach more family members, possibly including classes that involve spouses, newsletters and Spanish radio programs.
\end{abstract}

Chronic disease takes a substantial toll on the U.S. economy due to medical care and lost productivity. In 1995, the costs associated with heart disease, cancer, stroke and diabetes were approximately $\$ 250$ billion (Franzão 1996). Lifestyle factors, including highfat diets, lack of exercise and smoking, increase the risk of these chronic diseases earlier in life. The U.S. Department of Agriculture (USDA) has estimated that even small reductions of $1 \%$ in total dietary fat and saturated fat intakes and $0.1 \%$ in cholesterol could save more than 18,000 lives per year.

Although many Americans have improved their diets in the last 10 years, most are not meeting the 1995 U.S. Dietary Guidelines. According to the Third Report on Nutrition Monitoring in the United States (FASEB 1995), fewer than one-third of American adults meet the recommendation to consume five or more fruits and vegetables a day. In fact, between 1980 and 1992, food purchases dropped by $11 \%$ for vegetables and $22 \%$ for fruits. Although dietary intake of total fat, saturated fat and cholesterol has decreased over the last decade, intakes still remain above recommended levels for $75 \%$ to $79 \%$ of the population. Meanwhile, obesity, which increases the risk of many chronic diseases, is on the rise. More than one-third of adults and one-fifth of teens in the United States are now overweight (Kuczmarski et al. 1994). Although many people recognize that diet can lower their risk of chronic disease, they are often unable to improve their eating habits. In examining strategies for implementing the Dietary Guidelines, a committee from the Food and Nutrition Board stressed the importance of adapting the message to the needs of diverse audiences.

The Expanded Food and Nutrition Education Program (EFNEP) is a federally funded nutrition education program designed to help low-income families, especially those with young children, to improve their diets. Through a series of classes or individual contacts, trained paraprofessionals teach clients the basics of planning nutritious meals, budgeting and 
storing food safely. Research shows that EFNEP is effective in helping families improve their diets (Tredici et al. 1988).

Today, EFNEP in California faces many challenges as the low-income population becomes increasingly diverse. Between 1980 and 1990, the immigrant population in California increased by $80 \%$, a growth rate five times as high as that of the nonimmigrant population. Most of the influx has come from Mexico, the Philippines, China and Southeast Asia. Lifestyle changes for some of these groups are profound and may increase the risk of chronic disease. In California, recent immigrants from Mexico quickly adopt nontraditional foods, including sliced white bread, margarine, ready-to-eat breakfast cereals, salads, salad dressing, mayonnaise, flour tortillas and Kool-Aid or Tang. Salads and vegetable side dishes are consumed more often after immigration, but traditional dishes with cooked vegetables are prepared less often. These changes in vegetable consumption are also accompanied by increased fat intake in the form of salad dressings, mayonnaise, margarine and butter (Romero-Gwynn et al. 1993). Studies from Texas have shown that low-income Mexican-Americans in San Antonio eat higher-fat diets, weigh more and are more prone to diabetes than Mexicans in Mexico City (Stern et al. 1992).

Identifying health concerns, barriers to change and the values of diverse audiences is essential to successful nutrition education to reduce the risk of chronic disease. Market research with different ethnic groups indicates that people want personalized nutrition information that fits with their lifestyles. The objective of this article is to report current activities that EFNEP is undertaking in California to develop culturally appropriate tools to evaluate changes in food-related behaviors due to nutrition education and to assess the needs of Latino clients.

\section{Food Behavior Checklist}

EFNEP needs a rapid assessment tool that can be used across the state to evaluate the program and to provide

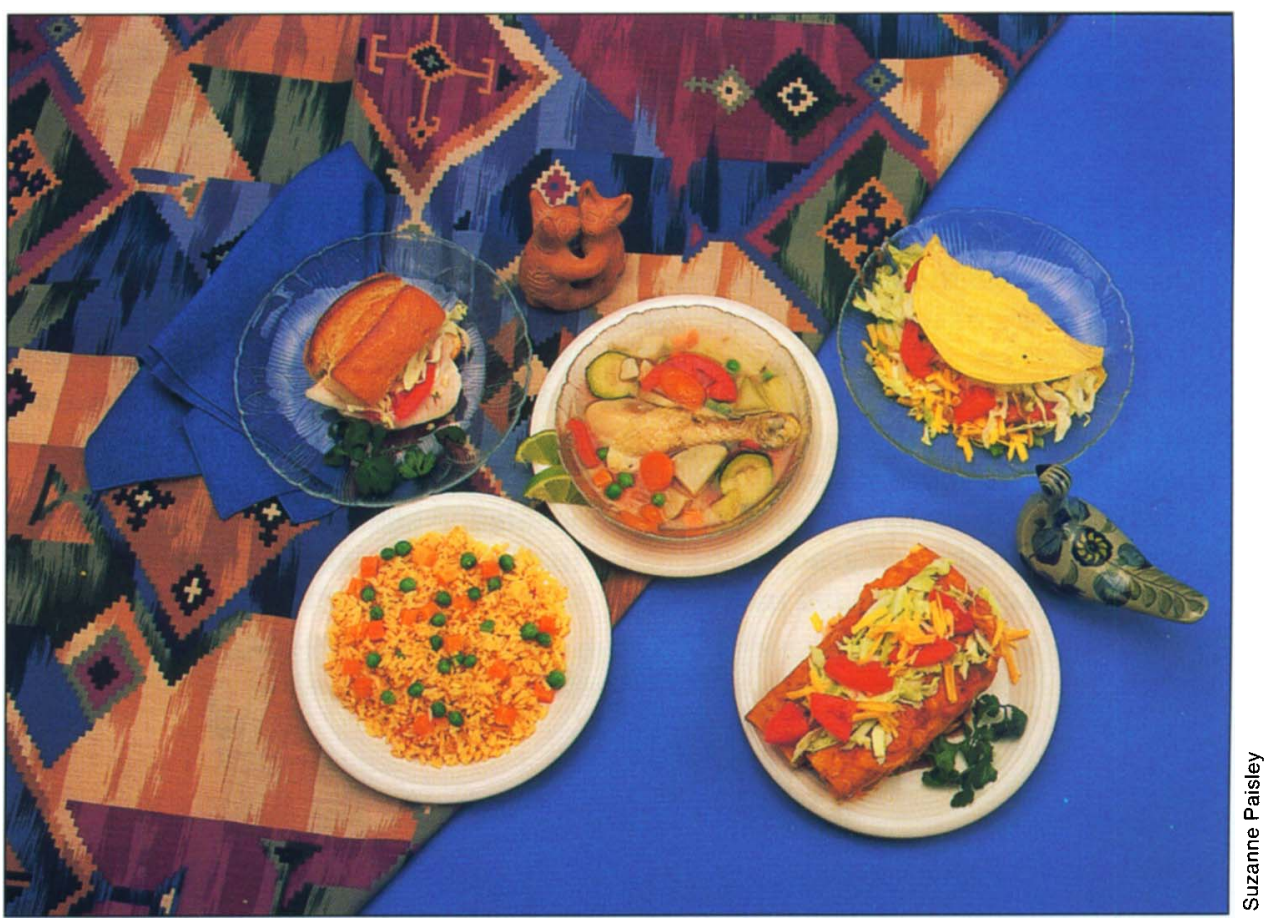

Extending meat dishes with vegetables and grains is an important skill taught in EFNEP classes.

direction. Ideally, different tools should be used with each cultural group, but this approach is not practical and would lead to problems in monitoring and interpreting the data. Therefore, in 1996 EFNEP pilot-tested a set of 48 questions about food-related behaviors and attitudes among 50 Spanish-speaking and 100 Englishspeaking women (primarily white and African-American). The purpose of this pilot study was to develop a Food Behavior Checklist with a core set of questions that work equally well with Spanish- and English-speaking clients EFNEP participants completed the pilot Food Behavior Checklist twice, before and after the series of EFNEP classes. Three 24 -hour dietary recalls were also collected before and after the classes.

We found a number of changes in food-related behaviors (tables 1 and 2). Pretest and posttest scores were available for only 35 Spanish-speaking clients, because 15 subjects did not complete all of the classes. Significant changes occurred in many areas, including type of milk consumed, use of oil and lard in cooking vegetables, meat thawing practices, use of the nu- trition facts on the food label and selection of fruits and vegetables as snacks. No change was observed in the frequency of drinking sodas. Spanish-speaking clients reported significant changes for a greater number of behaviors ( $>50 \%$ of the items) compared to the English-speaking clients (only $20 \%$ of the items, data not shown). Within each of the six topic areas shown in tables 1 and 2, at least one question was found that elicited a similar response in both English- and Spanish-speaking groups. EFNEP is currently conducting a randomized, controlled study to validate behavior change using these questions, as well as others in areas identified by the focus groups.

\section{Identifying diet influences}

In teaching classes, EFNEP paraprofessionals use curriculum materials developed by UC nutrition specialists. These materials cover menu planning, food shopping, food safety, fats, sugar, sodium and the food groups of the food guide pyramid. EFNEP participants are exposed to many nutrition messages, some of which prompt immediate behavioral change. However, 
sometimes participants would like to change other behaviors but cannot, due to family or financial pressures. Good evaluation tools need to track not only the behaviors most likely to change but also those areas that participants are still struggling to change.

Focus group discussion is a qualitative research method often used in social marketing to identify the needs, beliefs, opinions and values of the target audience. Usually six to nine people from the target group participate in a discussion guided by a trained moderator who uses carefully designed questions, probes and cues.

We recently used this approach in Fresno County in four focus group discussions with Latino EFNEP graduates (two Spanish-speaking and two English-speaking groups, $\mathbf{n}=29$ ). The purpose of these discussions was to identify major changes in food-related behavior that have occurred as a result of EFNEP nutrition education. We also wanted to identify areas that still need improvement, barriers to change and additional steps EFNEP might take to

TABLE 1. Changes in behaviors of Latino EFNEP graduates from the Food Behavior Checklist $(n=35)$

\begin{tabular}{|c|c|c|c|}
\hline \multirow[b]{2}{*}{ Topic } & \multicolumn{2}{|c|}{$\begin{array}{l}\% \text { Performing behavior } \\
\text { "usually" or "often" } \\
\end{array}$} & \multirow{2}{*}{$\begin{array}{c}\text { Significance } \\
(\mathrm{P}<)\end{array}$} \\
\hline & Pretest & Posttest & \\
\hline & ................. & ..................... & \\
\hline $\begin{array}{l}\text { Food buying/meal planning } \\
\text { 1. Do you shop with a list? }\end{array}$ & 42 & 71 & 0.001 \\
\hline 2. Do you use the Nutrition Facts on the food label? & 36 & 75 & 0.002 \\
\hline 3. Do you plan menus before shopping? & 44 & 63 & 0.031 \\
\hline 4. Do you compare food prices? & 67 & 88 & 0.045 \\
\hline 5. Do you make main dishes from scratch? & 11 & 15 & NS \\
\hline \multicolumn{4}{|l|}{ Food groups/variety/fiber } \\
\hline 6. Do you eat more than 1 kind of vegetable a day? & 54 & 88 & 0.001 \\
\hline 7. When you eat bread, is it whole wheat? & 45 & 83 & 0.007 \\
\hline 8. Do you eat more than 1 kind of fruit a day? & 65 & 91 & 0.008 \\
\hline 9. Do you eat fruits and vegetables as snacks? & 45 & 74 & 0.008 \\
\hline 10. Do you drink milk daily? & 59 & 72 & 0.045 \\
\hline 11. When you eat tortillas, are they corn? & 85 & 88 & NS \\
\hline 12. How many servings of fruit do you eat daily? & $73(>3)^{\star}$ & $71^{*}$ & NS \\
\hline 13. How many servings of vegetables do you eat daily? & $92(>3)^{*}$ & $79^{*}$ & NS \\
\hline \multicolumn{4}{|l|}{ Food safety } \\
\hline 14. Do you thaw food at room temperatures? & 75 & 15 & 0.001 \\
\hline 15. Do you leave perishables out of refrigerator for more than 2 hour & rs? 8 & 6 & NS \\
\hline 16. Do you wash your hands after handling raw meat? & 96 & 100 & NS \\
\hline 17. Do you wash surfaces after contact with raw meat? & 85 & 100 & NS \\
\hline
\end{tabular}

* Percentage of participants consuming more than 3 servings per day.

TABLE 2. Changes in food behaviors related to fat, sugar and sodium, from the Food Behavior Checklist $(n=35)$

\begin{tabular}{|c|c|c|c|}
\hline \multirow[b]{2}{*}{ Topic } & \multicolumn{2}{|c|}{$\begin{array}{l}\text { \% Performing behavior } \\
\text { "usually" or "often" }\end{array}$} & \multirow{2}{*}{$\begin{array}{c}\text { Significance } \\
(P<)\end{array}$} \\
\hline & Pretest & Posttest & \\
\hline
\end{tabular}

Fat

18. Do you put butter or margarine on vegetables

19. Do you remove the skin from chicken?

20. Do you eat low-fat instead of high-fat foods?

21. Do you trim fat from meats?

22. Do you use low-fat or skim milk?

23. Do you snack on chips?

24. Do you put sour cream or other sauces on vegetables/potatoes?

25. Do you prepare vegetables with lard or oil?

26. Do you use low-calórie/fat salad dressings?

27. Do you put butter or margarine on bread, etc.?

Sodium

28. Do you add salt to food?

29. Do you buy low-sodium processed foods?

$\begin{array}{rrl}15 & 11 & 0.005 \\ 68 & 89 & 0.005 \\ 48 & 94 & 0.001 \\ 78 & 88 & 0.03 \\ 50 & 91 & 0.01 \\ 33 & 9 & 0.001 \\ 32 & 9 & 0.024 \\ 32 & 8 & 0.0167 \\ 22 & 35 & \text { NS } \\ 13 & 14 & \text { NS } \\ & & \\ 85 & 57 & 0.001 \\ 37 & 57 & 0.004 \\ & & \\ 8 & 8 & \text { NS } \\ 21 & 24 & \text { NS }\end{array}$

facilitate change. To get a cultural perspective, we kept the focus group questions open-ended. For example, to find out what additional changes clients would like to make, we asked, "Think about the foods you and your family buy. If you could change one thing, what would it be?" Each focus group discussion took about an hour and a half and was tape recorded. We examined the co-moderator's notes and a transcription of the tapes for major themes.

\section{Focus group responses}

\section{Changes in food-related behav-}

ior. When asked about changes that they had made as a result of EFNEP classes, several Spanish- and Englishspeaking participants reported using less fat. The Spanish-speaking women claimed to cut fat by cooking tostadas in the oven and by using less oil and lard in preparing beans, eggs and vegetables. The English-speaking women also mentioned using turkey instead of beef, removing skin from chicken and steaming rather than frying meat. Other changes included using more vegetables, fruit and whole wheat bread; switching to a lower fat milk; thawing meat in the refrigerator instead of on the counter; and reading labels.

Participants also reported changes in shopping practices. The Spanishspeaking group claimed to be spending less on food after EFNEP, with comments such as, "Before I go, I write down everything I will need. ... Before I would spend $\$ 70$ to $\$ 80$ and now I spend a lot less." The English-speaking participants emphasized that they were more critical in comparing labels and prices than before EFNEP. For example, one participant commented, "I would get anything that was on sale, wouldn't look at the brands, would just get the cheapest; but now, even if it's a little more expensive, I get what will be good for my health." Both English-speaking and Spanish-speaking participants felt that they had learned to increase variety while saving money, especially by extending meals with vegetables and grains. For example, one Spanish-speaking woman 
said, “I learned what to do if I don't have a lot of food - combine foods with others to make it stretch, like a little ground meat, a piece of potato, rice, vegetable - not just pure meat or rice."

\section{Changes Latinos would like to}

make. In addition to identifying behavior changes due to EFNEP, we were interested in finding out which practices the participants felt they still needed to change. Both English- and Spanish-speaking groups responded that they (or other family members) were consuming too much meat, sweetened cereal, donuts and sweet bread, fast food, soda, Kool-Aid and salt. Some participants from the Spanish-speaking group felt that they or their husbands ate too many tortillas.

Family pressure was the most common reason given for not being able to make these changes. Time, convenience, cost, custom and lack of will power were mentioned less often. For example, one English-speaking woman said, "I want my husband not to eat so much meat. He has to have meat at almost every meal. ... I don't want him to have a heart attack and die early like his dad." About fast food, one Spanish-speaking woman said, "It's difficult for me because I don't like to cook on Saturdays and Sundays. I know the food on the street (fast food) has a lot of fat. I would like to change but I can't."

Cost was mentioned as a barrier, but not as often as one might expect when working with low-income families. Several women said that they used Kool-Aid instead of juice because Kool-Aid is so inexpensive and they run out of juice very quickly. Some women mentioned that cost might be more of an issue if they did not receive free vouchers for food from the Special Supplemental Nutrition Program for Women, Infants, and Children (WIC). The influence of customs or habit was reflected in such comments as, "It has to do with the way you were raised. If you are used to the salt, without the salt it has no flavor." Several women mentioned that self-discipline or will power is a factor, with comments such as, "I haven't really been putting my whole effort into it," and "To want to do it is to be able to do it (el querer poder es poder)."

How EFNEP can help Latinos make additional changes. We asked the participants what else EFNEP could do to help them improve their eating habits. The most common response across all groups was a desire for more classes, covering topics such as feeding young children, preserving foods, preventing illness (including diabetes), keeping disciplined about eating, and exercising. In both Englishspeaking groups, clients asked for additional simple, inexpensive, tasty recipes and newsletters to help them keep motivated after the program is over. Spanish-speaking clients did not ask for more written materials but expressed their interest in seeing food demonstrations and tasting the foods. English-speaking groups recommended that the program seek ways for the whole family to participate, not just the mother or parents. They suggested holding classes in schools or work sites, printing columns in the sports section of newspapers and airing messages on Spanish radio as ways to reach other family members. More English-speaking than Spanishspeaking women said they thought their husbands would come to a nutrition class. However, both groups identified personal contact in doing outreach as important in recruiting more participants into the classes.

\section{Conclusions}

The pilot study of the EFNEP Food Behavior Checklist and the focus group discussions in Fresno yield a consistent picture of key behaviors that Latinos modify as a result of EFNEP. In interpreting these results, keep in mind that EFNEP graduates may be more motivated than others who drop out of the program. Latina EFNEP participants claim to use less fat in cooking, to buy more vegetables and low-fat milk and to read the nutrition facts labels when shopping. The next version of the EFNEP Food Behavior Checklist, which is currently being validated, monitors changes in these behaviors, as well as others that participants felt needed improvement.
Specifically, new questions were added to track consumption of fried meat, sweetened drinks and cereals and fast food. Family pressure was mentioned as a major barrier to change, along with time, convenience, cost, custom and self-discipline. EFNEP nutrition educators working with Latinos need to find new ways to sustain changes and to reach more family members. Avenues to explore include newsletters, newspaper, Spanish radio programs and classes that involve other family members. Focus group discussions can yield valuable insights for program monitoring and can identify where additional efforts are needed.

L.L. Kaiser is Community Nutrition Specialist, Department of Nutrition, UC Davis; J.M. Sutherlin is Nutrition, Family and Consumer Science Advisor and S.C. Yoshida is Program Representative, both with UCCE Fresno County; S.P. Murphy is State EFNEP Coordinator and S.D. Bresnick is a Doctoral Student, both with the Department of Nutrition, UC Davis.

The authors thank Save Mart Supermarket for its support of this study and specifically the Save Mart in Sanger, which was the site for the Fresno County pilot study and focus group discussions.

\section{References}

Federation of American Societies for Experimental Biology, Life Sciences Research Office. Prepared for the Interagency Board for Nutrition Monitoring and Related Research. 1995. Third Report on Nutrition Monitoring in the United States. Executive Summary. US Gov. Printing Office. Washington, DC. 51 p. Franzão E. 1996. The American diet: a costly health problem. Food Review 19(1): 2-6.

Kuczmarski R, Flegal K, Campbell S, Johnson C. 1994. Increasing prevalence of overweight among U.S. adults. JAMA 272:205-11.

Romero-Gwynn E, Gwynn D, Grivetti L, MacDonald R, et al. 1993. Dietary acculturation among Latinos of Mexican descent. Nutrition Today 28(4):6-12

Stern MP, Gonzalez C, Mitchell BD, et al. 1992. Genetic and environmental determinants of type II diabetes in Mexico City and San Antonio. Diabetes 41:484-92.

Tredici AM, Joy AB, Omelich CL, Laughlin SG. 1988. Evaluation study of the California Expanded Food and Nutrition Education Program: 24-hour food recall data. J Am Diet Assoc 88: 185-90. 